Athens Journal of Business \& Economics -

Volume 7, Issue 4, October 2021 -Pages 349-364

\title{
Integration of Agile Approaches in SME's Product Development: Demand Analysis and Concept Development
}

\author{
By Manuel Niever ${ }^{*}$, Han Jennifer Trinh ${ }^{ \pm}$, Roman Kerres ${ }^{ \pm}$\& \\ Carsten $\mathrm{Hahn}^{+}$
}

\begin{abstract}
In times of a complex, uncertain and dynamic world with increasingly faster product life cycles agile approaches in the early phase of product development are demanded in small and medium sized enterprises (SME's). Despite the high demand, there is still no generally valid and need-specific solution concept for the integration of agile approaches due to different company specific requirements such as the level of maturity, experience and application purposes. Within this research, the question about the actual needs as well as the corresponding design of a concept for integrating agile approaches in product development for SME requirements is tackled. In order to identify existing challenges in the field of agile product development an empirical study with eleven mechanical engineering companies is conducted and analyzed. By using agglomerative-hierarchical clustering, three distinct types of SME's with similar needs are structured. As a result, this research proposes a systematic procedure, enabling SME's to be clustered by their needs and enable the integration of agile approaches through a problem-oriented roadmap with specified recommendation of actions. Enhancing the integration and application of agile approaches effectively in product development projects, the level of agility appropriate to the situation and needs must be identified and introduced. Therefore, the potential that arises from the process-oriented support of the product development teams in the early phase of innovation projects will be outlined.
\end{abstract}

Keywords: agile approaches, needs analysis, small and medium sized enterprises, clustering, product development, mechanical engineering

\section{Introduction}

Many SME's are confronted to counter the pressure of the VUCA (volatile, uncertain, complex, and ambiguous) world (Nandram and Bindlish 2017) and aim at integrating agile approaches due to the necessary adaptivity and flexibility (Dose and Drexler 1988, Kastelle 2013). Especially in the early phase of product development, in which the product gets initially designed and can usually still be flexibly adapted, the use of agile approaches can be of great advantage (Albers et

\footnotetext{
*Research Assistant, University of Applied Sciences Karlsruhe, Germany. ${ }^{ \pm}$Master Student, University of Applied Sciences Karlsruhe, Germany.

${ }^{\ddagger}$ Research Assistant, University of Applied Sciences Karlsruhe, Germany. ${ }^{+}$Professor, University of Applied Sciences Karlsruhe, Germany.
} 
al. 2019a, 2f., VersionOne Inc. 2019).According to different studies these advantages are increased flexibility to respond to changes and handle complexity, increased transparency and improved communication within the development teams as well as an improved satisfaction of customer needs (Atzberger et al. 2020, VersionOne Inc. 2019, we.Connect 2018).

Despite the benefits as well as the increasing need of agility, there are only a few SME's in the mechanical engineering context using agile approaches in their product development because of generic and therefore insufficient instructions of integrating agile approaches (Fritsch and Juschkat 2019, VersionOne Inc. 2020). The majority of instructions are based on specific best-cases, designed for specific companies and methods regarding the needs and features of individual SME's (Gloger and Margetich 2014, 90f, Mathis and Leffingwell 2018, 90f). This makes the integration of agile approaches into other companies more difficult and requires a high degree of customization. Heimicke et al. (2019), who evaluated potentials and limitations of the approaches in mechatronic system development, points out that the current approaches are well suited for their respective purposes. "However, they lack the conscious integration of technical or process-related knowledge" (Heimicke et al. 2019).

Since there is still little experience in the research field of the integration of agile approaches into the early phase of product development, this research investigates which practical problem areas exist, how a concept for company specific requirements and characteristics needs to be set up and how this can be facilitated by process oriented support in order to promote agile product development in SME's. To achieve the goal of desinging a new generally adaptable but differentiated approach to integrate various agile approaches, a clustering has been conducted. This enables a grouping of different SME's with similar requirements. Based thereon cluster-specific measures can be derived and presented in the developed concept.

\section{Literature Review}

The state of art describes the product development in SME as well as different agile approaches in product development and their action systems of methodically support for the implementation through specific roles.

\section{Product Development in SME}

Small and mid-size enterprises are not able to apply the state-of-the-art research which is based on an understanding of larger corporates as they have unique characteristics. As Welsh et al. (1982) already stated, SME's are not miniature versions of large corporates. Meaning that methods and techniques, that are working for large corporates do not necessarily work also for SME's. Therefore, research needs to consider companies in a more granular view.

When it comes to new product development and innovation management, SME's are facing different challenges then large corporates. Limited resources (Bicen and Johnson 2015, Massis et al. 2018), family influence (Kammerlander 
and Prügl 2016), risk aversion of following generations (Kammerlander and Ganter 2015) and a low degree of process formulization (Berends et al. 2014) are just a few factors which are discussed in the current literature. Especially the low degree of formalization of SME's leads to low internal bureaucracy. Therefore, in terms of innovation they rather follow an experimental approach with close resource orientation instead of a highly formalized process (Berends et al. 2014, Massis et al. 2018). Thus they seldom pursue a systematic and method-based collection of information and ideas in the product development process. Furthermore, agile approaches can only rarely be found in the product development of SME's (VersionOne Inc. 2020).

\section{Agile Approaches in Product Development}

One of the most complex processes in companies are the innovation processes as they are characterized by a high degree of uncertainty regarding the problem and solution space (Schoeneberg 2014, 65ff). To classify problems in product development the two models Stacey Matrix and Cynefin Framework (see Figure 1) can be applied. They show that agile approaches are suitable if the described situation or process is particular complex or chaotic while complicated and simple problems can be solved by traditional plan-based methods (e.g., the waterfall method) (Fuchs et al. 2019, 202f). Hereby the Cynefin Framework (see Figure 1, left) divides problems into simple, complicated, complex and chotic problems. Whereas the Stacey Matrix sorts these 4 problem types regarding the scale of the problem and the solution.

Figure 1. Cynefin Framework and the Stacey Matrix
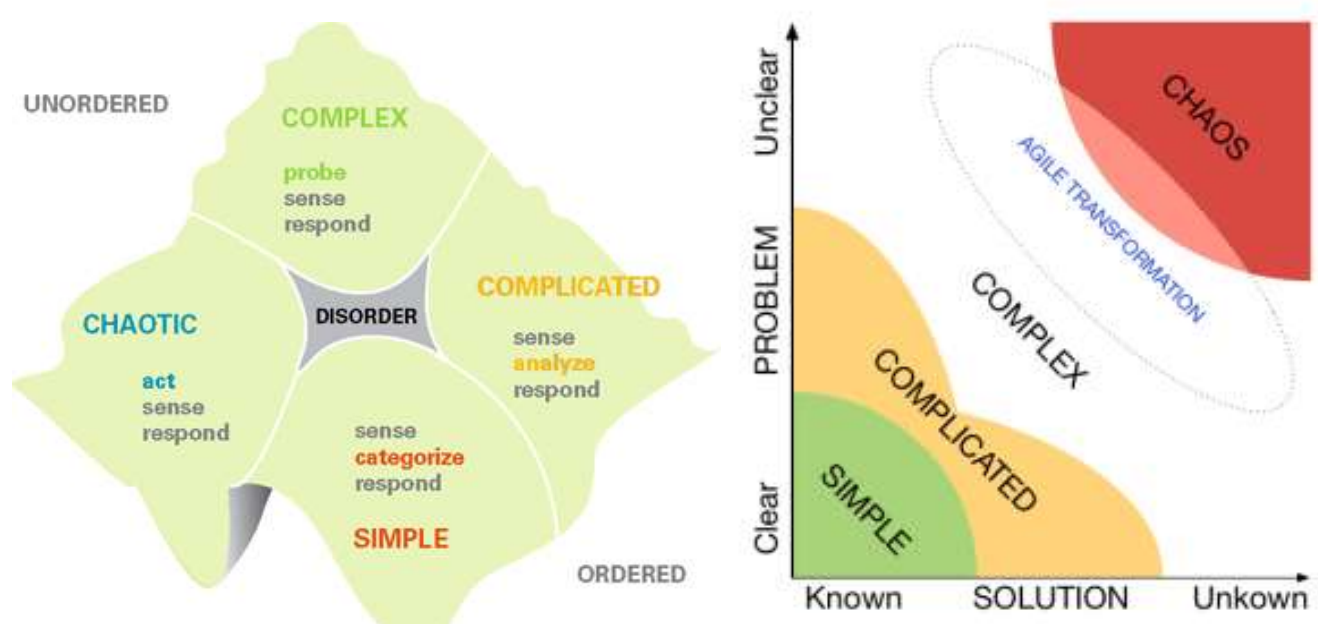

Source: Giom. Blog. 2019, Snowden and Boone 2007.

To handle the complexity, different approaches such as SCRUM, Design Thinking, lean start-up as well as scaled approaches like $\mathrm{LeSS}^{1}$ and $\mathrm{SAFe}^{2}$ are used in product development nowadays (Atzberger et al. 2020, Heimicke et al.

\footnotetext{
${ }^{1}$ LeSS stands for "Large Scale Scrum".

${ }^{2} \mathrm{SAFe}$ stands for "Scaled Agile Framework".
} 
2019). Further approaches are in research, for example the systematic approach of ASD-Agile Systems Design which handles the situation-adequate integration of agile elements into mechatronic system development (Albers et al. 2019b).

The agile approach of Design Thinking focuses on customer and user needs and iteratively determine the needs and requirements in an early phase. (Plattner, Meinel and Leifer 2011) In the agile project management framework Scrum, this is done through several feedback rounds in which Minimal Viable Products (MVP) are presented and evaluated until the product finally complies with the customer's needs. (Schwaber 2017) The approach of ASD - Agile Systems Design focuses on a systematic combination of structuring and flexible elements in the product development process in order to support development teams in mechatronic system development. As every project is unique, ASD does not provide readymade instructions, but supports teams in using the right methods in the development process to enable agility. (Albers et al. 2019b).

\section{Enabling Agile Product Development through Methodical Support}

To methodically support the realization of agile approaches, current agile approaches as SCRUM, Design Thinking or ASD-Agile System Design enhance the implementation by the involvement of a process oriented role such as the Scrum Master, Design Thinking Coach or Innovation Coach. Additionally, a common role in practice to introduce agile approaches in general is the Agile Coach (Barafort et al. 2014, O'Connor and Duchonova 2014). The Scrum Master is responsible for promoting and supporting Scrum by helping everyone understand the Scrum theory, practices, rules, and values (Schwaber 2017). In comparison the Design Thinking Coach works with the development teams and focuses on a context-related, goal-oriented and sustainable application of the Design Thinking approach (Plattner et al. 2011). Innovation Coaching is a specialized concept for process-oriented support of people in agile product development projects. Core elements are the communication of agile ways of thinking, the ability to apply various methods appropriate to the situation and need of the teams situation as well as the conscious control of team development. (Niever et al. 2019) These different roles are implemented for the methodically support of development teams for specific agile approaches with the goal to establish a dynamic, user-centered and goal-oriented innovation culture within a project and furthermore scaled within the organization. Global studies show the high relevance of methodically support for the implementation of agile approaches and furthermore that internal agile coaches are the most valuable in helping to scale agile approaches in organiszations (VersionOne Inc. 2019, we.Connect 2018).

\section{Integration of Agile Approaches in Product Development}

In previous literature, a variety of different applications and instructions are available for integrating agile approaches into the product development process. Of these, three frequently used types of approaches in particular were identified 
(Gloger and Margetich 2014, 98f, Leffingwell 2020, Mathis and Leffingwell 2018) and will be presented with some examples in the following.

The first type of integration approaches are top-down measures for problems based on practical experience. Exemplary instructions for action are encouragement of self-organization and decision-making, promoting employees with agile coaching competences or room furnishings decision enhancing agile work (Gloger and Margetich 2014, 98f). There are also measures designed to fight problems during the introduction of SCRUM to resolute residual obstacles e.g., by autonomous teams and/or transition teams, promoting employees with integration roles and other adaption measures of organizational structures (Gloger and Margetich 2014, 104f). All these exemplary approaches have in common that agility is introduced via management. Hereby it is noticeable that they often include measures to combat the problems that arise during the introduction of agility concerning its acceptance.

Another type of approach to introduce agility into an organization is the stepby-step instruction (see Figure 2). The basis of this type is the general change management approach of Kotter and Cohen (2012) with the eight steps of changemanagement which refers to the introduction of new methods into existing organizations.

Figure 2. Kotter's Eight Steps of Change Management

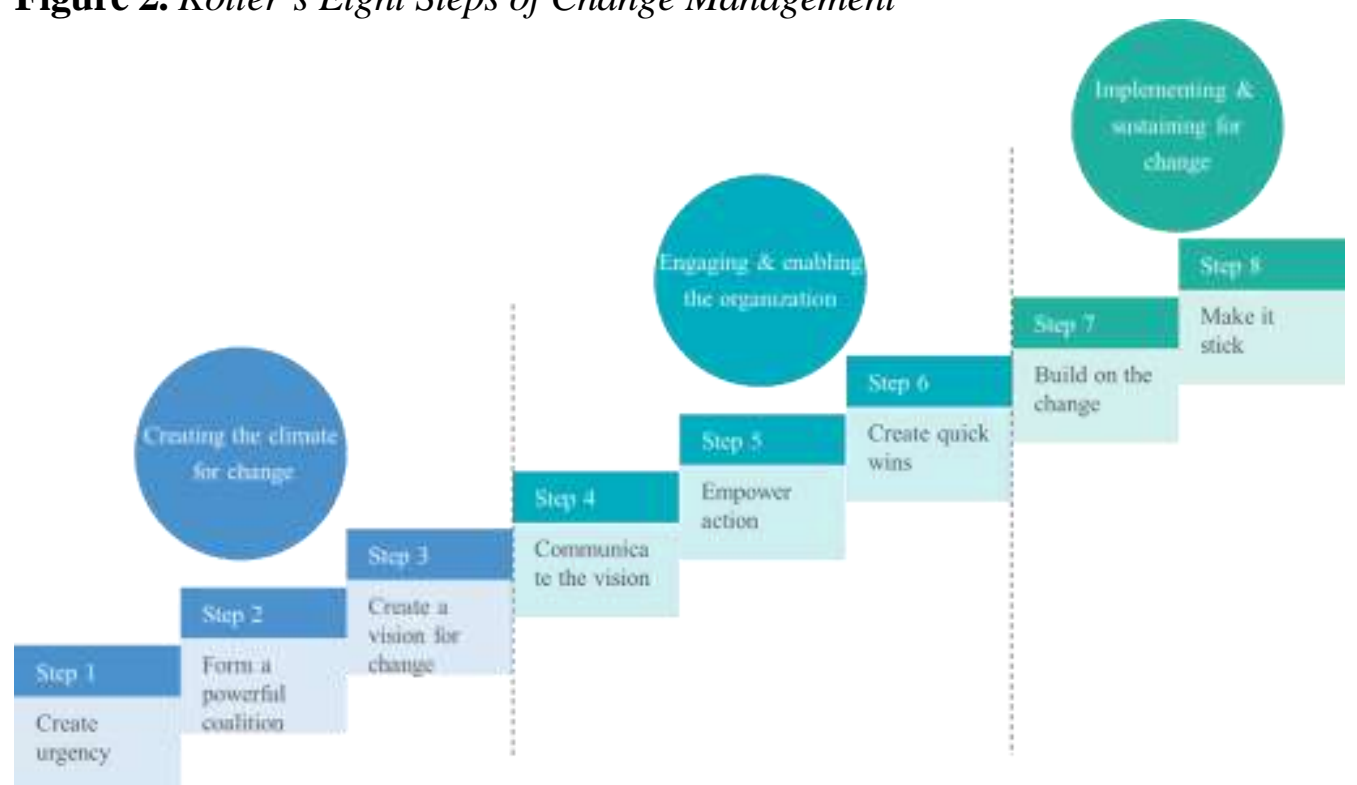

Source: own presentation based on Kotter and Cohen 2012.

Another similar step-by-step guide has been introduced in 2008 by Nanda, Groysberg, Prusiner with the 7+1 steps to encounter SCRUM Introduction with resistance (Gloger and Margetich 2014, 124f). Both methods do not hold a recommended path for a specific company and therefore includes the risk of not having the right problem-oriented measure for the integration of agile approaches into different organizations.

The third type of approach is a general concept for a scaled introduction of SCRUM in an organization depending on the size of the company. Examples are 
the roadmap Introduction of Scaled Agile Framework (SAFe) and Large Scaled Scrum (LeSS). SAFe scales Scrum into four formats with different suggested approaches of integration to improve the cooperation of Scrum application based on the number of employees and presents a need-based guidance at the enterprise level (Leffingwell 2020). In comparison, LeSS suggests two different design frameworks based on the number of teams on which Scrum is applied to and focuses on product development (Vodde and Larman 2005). Thus SAFe is focused on a need-based guidance at the enterprise level while LeSS is similar to the paper approach in its focus on product development. Nevertheless, SAFe and LeSS are common models in practice which refer exclusively to the introduction of the specific agile approach of Scrum (Maximini 2018, 121f, Siedl 2018, p. 76).

\section{Research Methodology}

According to the current state of research, there are many approaches how companies can proceed in order to integrate certain agile approaches in their company (Gloger and Margetich 2014, 98f, Leffingwell 2020, Mathis and Leffingwell 2018). Nevertheless, there are many challenges and open questions how companies, especially SME, can successfully integrate agile approaches, since there are mainly company-specific best practices available for certain agile approaches. These are only suitable for specific companies after thorough examination, major adjustments and are therefore not easy to transfer. To ensure a situation- and need-specific integration of agile approaches into organizations the requirements and organizational structures must be taken into account. Thus, the research question arises, what are the current challenges of companies by the implementation of agile approaches in product development and which support is needed in their business situation? This research investigates the actual challenges and potentials in order to identify which concepts of support are applicable. Build upon these findings requirements are derived for an overarching concept to enable the implementation of agile approaches in product development according to the situation and needs of the companies.

The applied methodical research approach is based on the four phases of the Design Research Methodology (DRM) and intends a scientific and structured research to ensure a scientifically sound result (Blessing and Chakrabarti 2009, Lind 2017, p. 39). In the first phase, the theoretical foundation is built. In order to form a theoretical basis for further research and to identify the research gap, the status quo of the product development integration measures of agile approaches and methodical support roles are presented on the basis of benchmark analysis and method comparisons through literature research.

To guarantee a company-specific and up-to-date practical concept, the second phase, Descriptive Study I, is realized by an empirical study in the specification of 11 expert $^{3}$ interviews of different companies in the mechanical engineering

\footnotetext{
${ }^{3}$ e.g., head of product development, product developer with agile experience, agile coaches working in the product development. Target group were experienced professionals in product development with a leading role the innovation process.
} 
context. For this purpose, two hypotheses for different types of companies with similar needs were derived from the theoretical results and validated with the empirical study of the 11 qualitative expert-interviews:

1) SME's have the core need to integrate and apply agile approaches as efficiently as possible on a smaller scale in order to realize innovations with limited resources due to their scarcity of resources. ${ }^{4}$

2) SME's without agile experience have the core problem of not having enough know-how to implement and integrate agile approaches in their company. ${ }^{5}$

Within the Prescriptive Study, the obtained data is analysed, whereas the main focus is to determine requirements and criteria for the different company situations. A clustering of the heterogeneous individual companies based on the data enables the development of a cluster-specific integration concept with problem-oriented recommendations for action. Here, the agglomerative method of hierarchical clustering is used, as this approach enables an increasing number of clusters with decreasing distance, in order to select the smallest possible number of clusters that makes sense. Furthermore, it ensures a generalized concept which can be transferred to different companies. Since the empirical data are available in categorical form, they are loaded into a Python script and normalized on a scale of 0 - 1 with a min-max transformation to scientifically prepare and enable the answers to be interpreted. ${ }^{6}$ The scaled data is then divided into clusters using the linkage method. ${ }^{7}$ Hereby we use the Ward distance method to define the distance in the linkage procedure. Thus two clusters whose increase in variance by merging them is the smallest, are combined into one common cluster (Cleff 2019, 417f). In order validate its performance, the developed concept was applied at a practical workshop, according the Descriptive Study II. Against this background, the results were evaluated and action measures are derived (Lind 2017, 39f).

\footnotetext{
${ }^{4}$ This hypothesis is based on the characteristic of SME's compared to large corporations to have scarcer resources. Accordingly, it is in their increased interest to apply agile methods without high capital expenditure and to develop innovations as efficiently and effectively as possible.

${ }^{5}$ This hypothesis is based on the assumption that some SME's have neither the capacity nor the know-how to deal with the implementation and application of agile methods.

${ }^{6}$ The min-max rule thus sets the highest value of the variable (in this case per column in figure 5) as 1 and the lowest value of the variable as 0 . Using this formula, the data produces is scaled and normalized data, which now successfully lie between 0 and 1 and can therefore be processed further. Narang 2017, p. 614.

${ }^{7}$ An agglomerative clustering algorithm, in which each object first forms a cluster and then the clusters that have already been formed are gradually combined into larger and larger clusters until all objects belong to one cluster).
} 


\section{Results}

Current Challenges of Companies by the Implementation of Agile Approaches in Product Development

To ensure a situation- and need-specific integration of agile approaches into organizations, the needs and organizational structures must be taken into account. In order to identify current challenges of companies and their need for support, the truth content of the presented hypotheses are investigated by analyzing the 11 expert interviews. The results of the study, which have been redacted for data protection reasons, are illustrated in the line chart below (see Figure 3). It illustrates the identified and evaluated problems in the application of agile approaches in the product development of eleven machine-engineering companies. On the abscissa the identified problems are listed and the ordinate describes the severity of the encountered problem using the Likert scale ( 1 being very weak and 5 being very strong).

Figure 3. Data Analysis of Problem Fields in Agile Integration and Application

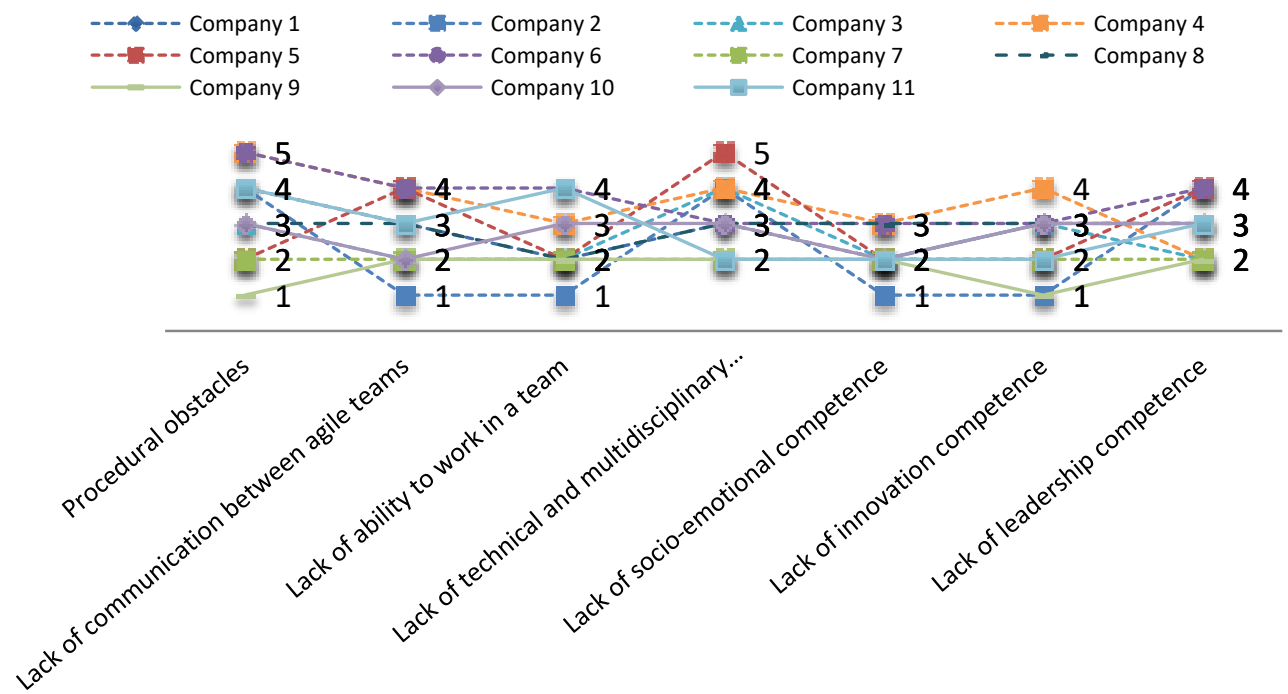

As a result of the qualitative data analysis the following can be noted: The problems a company faces in integrating and applying agile approaches do not depend on the size of the company, but mainly on the predominant degree of agile approaches and the process-related obstacles in the companies. Employees find it difficult to escape the familiar hierarchical structures and to deviate from the usual waterfall methodology. The hypothesis analysis of the collected empirical data thus shows that the hypotheses are not completely consistent. For example, there are SME's as well as large corporates with high and low process-related obstacles when using agile approaches.

Furthermore, it is noticeable that all companies have serious difficulties with the lack of know-how of agile approaches in product development. However, the 
need for agile know-how as well as the need for better communication between and in agile teams are current problems but first must be considered individually for all companies and cannot simply be categorized. Another derivative is the existing lack of understanding of the purpose and added value of agile approaches and accompanying methods for the projects, which prevents their successful application.

The study results show a need for support by the application of methods and tools in the early phase of the product development. Even with the understanding of the methods it is difficult to apply them in the right situation to help the development team to increase their ability to innovate. The application of the right methods in time comes with the big challenge of implementing the appropriate degree of agility that is suitable in the corresponding situation.

Additionally, the challenge arised, that most of the experts had parallel responsibility for an agile project and tasks of series development. To manage the challenge of running the operating business with incremental improvements as well as simultaneously exploring new possibilities can be assigned to the difficulties of an ambidextrous management. To handle these two action-oriented ways of thinking at the same time a support regarding the prioritization and practical realization would be very valuable.

According to the pre-formulated hypotheses three clusters of companies would result with the respective assumptions. Since the hypotheses could not be fully confirmed in the empirical study and companies also show problems in unforeseen fields, the sole consideration of the number of employees and the agile degree of the company as a clustering dimension is not sufficient to carry out a clear clustering. This allows two conclusions to be drawn for clustering. First, the number of clusters cannot be determined a-priori. Secondly, clustering must be designed in an interpretable way. Finally, companies that are as similar as possible should be grouped together in order to be able to derive cluster-specific action measures that really address the problems for the respective cluster.

\section{Derived Cluster-Specific Concept for Integrating Agile Approaches}

With the described status quo in the state of the art as well as the analysis result of the current challenges and needs for support, the research gap in the area of implementing agile approaches in different companies is shown. With the derived requirements for an overarching concept to enable the implementation of agile approaches in product development a problem-oriented concept is developed build upon three parts cluster allocation, cluster-specific roadmap, exemplary tools and methods (see Figure 4). 
Figure 4. Cluster-Specific Concept for Agile Integration

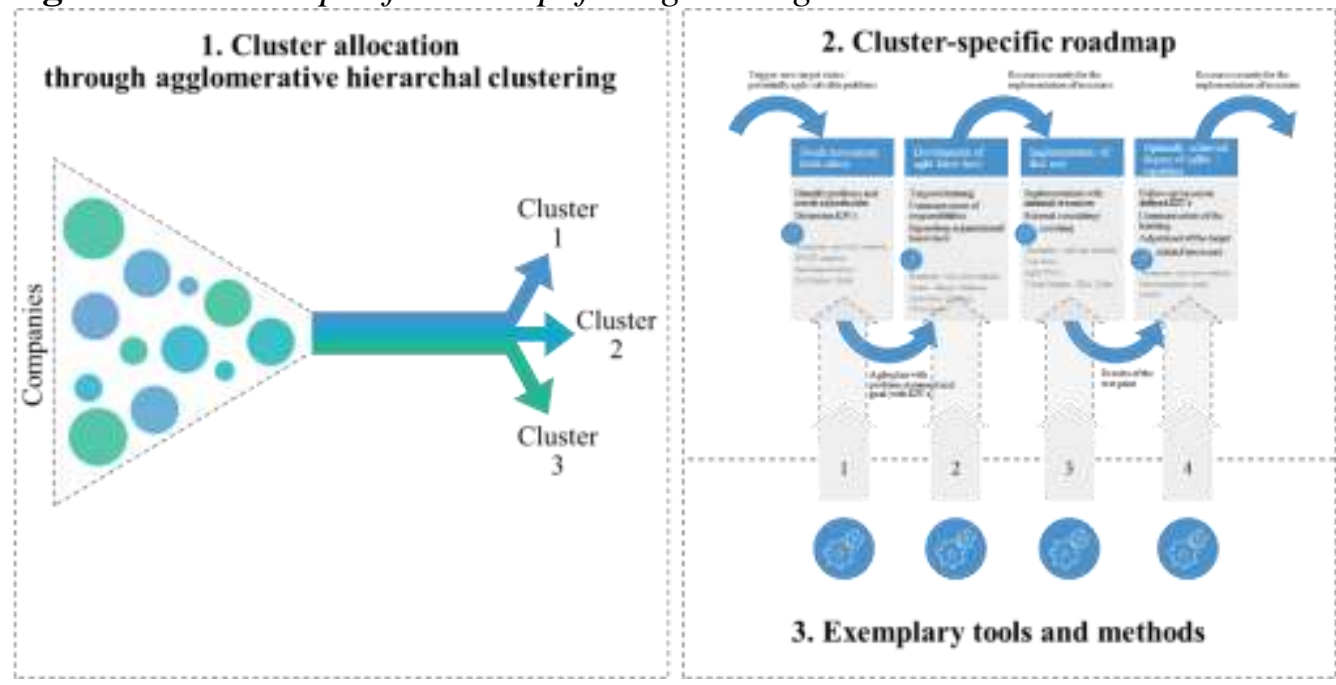

$I^{\text {st }}$ Part of the Concept: The Problem-Oriented Clustering

After applying the ward method, explained in the methodology, the clustered companies are presented in a dendrogram (see Figure 5). To determine the optimal cluster number and thus the final clusters, a dividing line must be drawn where the heterogeneity (the increasing distance) increases the injections (the number of clusters). Here the elbow plot is created as it can indicate when such jumps occur (Cleff 2019, p. 418). Under consideration of the elbow plot and previous knowledge of the analysis of the surveys (Kassambara 2017, $101 \mathrm{f}$ ), three clusters were formed ex-post as a result.

Figure 5. Dendrogram of Aggloerative-Hierarchical Clusterin

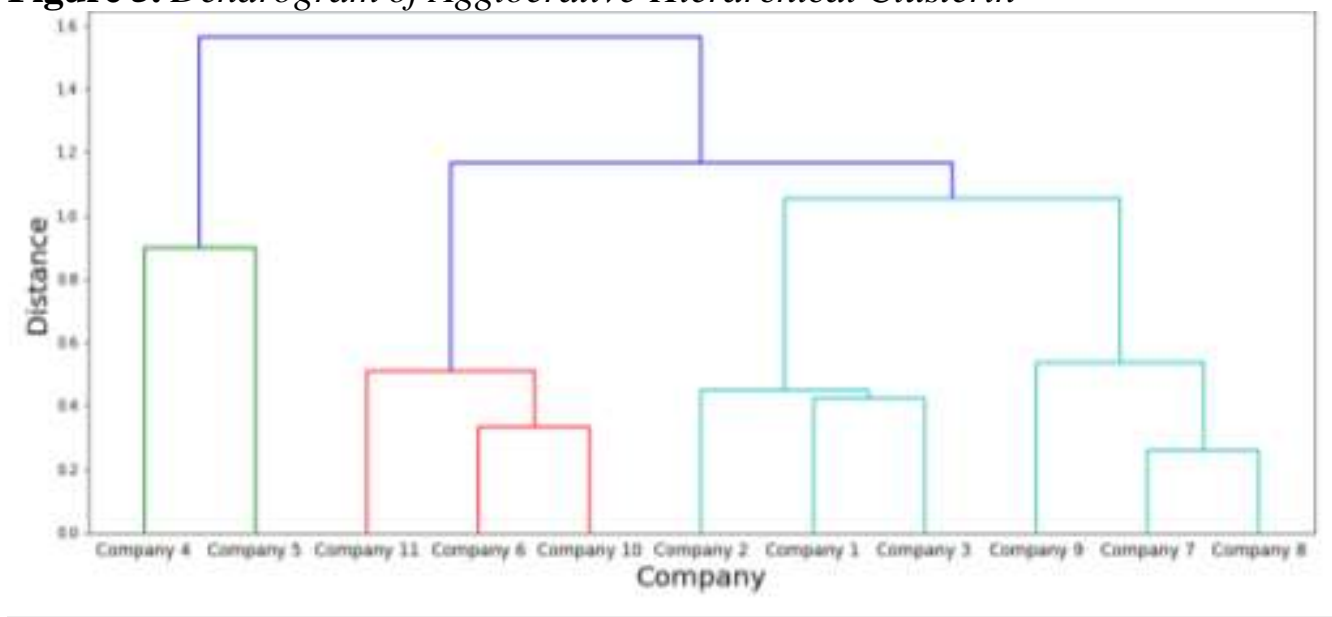

The clustering allows an allocation into groups of companies with similar agility needs and results in three clusters with following features (Table 1). 
Table 1. Resulting Cluster

\begin{tabular}{|c|c|c|}
\hline $\begin{array}{l}\text { Cluster 1: } \\
\text { No or few agile } \\
\text { experience }\end{array}$ & $\begin{array}{l}\text { Cluster 2: } \\
\text { Agile experience without } \\
\text { procedural obstacles }\end{array}$ & $\begin{array}{l}\text { Cluster 3: } \\
\text { Agile experience with } \\
\text { procedural obstacles }\end{array}$ \\
\hline $\begin{array}{l}\text { - Degree of optimal agile } \\
\text { product development } \\
\text { unclear } \\
\text { - Know How - Lack: } \\
\text { Organization and new } \\
\text { methods } \\
\text { - Lack of communication } \\
\text { between product } \\
\text { development teams } \\
\text { Lack of personnel } \\
\text { resources } \\
\text { High risk }\end{array}$ & $\begin{array}{l}\text { - Agile know-how usually } \\
\text { through internal training } \\
\text { - Lack of understanding and } \\
\text { application of agile } \\
\text { approaches } \\
\text { - Goal: Extend the } \\
\text { methodology toolbox (e.g., } \\
\text { SAFe approach) for } \\
\text { optimized and integrated } \\
\text { product development } \\
\text { - Communication problems }\end{array}$ & $\begin{array}{l}\text { - Know How - lack in } \\
\text { agile approaches (quality } \\
\text { assurance is missing) } \\
\text { - Procedural obstacles } \\
\text { - Product Owner is the } \\
\text { Manager (not always } \\
\text { suitable) } \\
\text { - Management support } \\
\text { missing (necessary for } \\
\text { fundamental change) } \\
\text { - Organizational } \\
\text { structures/projects set too } \\
\text { late for agile application }\end{array}$ \\
\hline
\end{tabular}

\section{$2^{\text {nd }}$ Part of the Concept: The Cluster-Specific Roadmap}

To integrate agile approaches in a problem-oriented way, corresponding cluster-specific roadmaps are formed based on the findings of the clustering and state of the art problem solving methodologies. The diverse problem severity of the three differentiated clusters is analyzed in addition with the clustered findings of our empirical study and theoretical approaches. Based on this knowledge cluster-specific approaches and recommendations for action are derived to ensure a problem-oriented integration of agile approaches.

Figure 6. Roadmap to Integrate Agile Approaches for Cluster 1

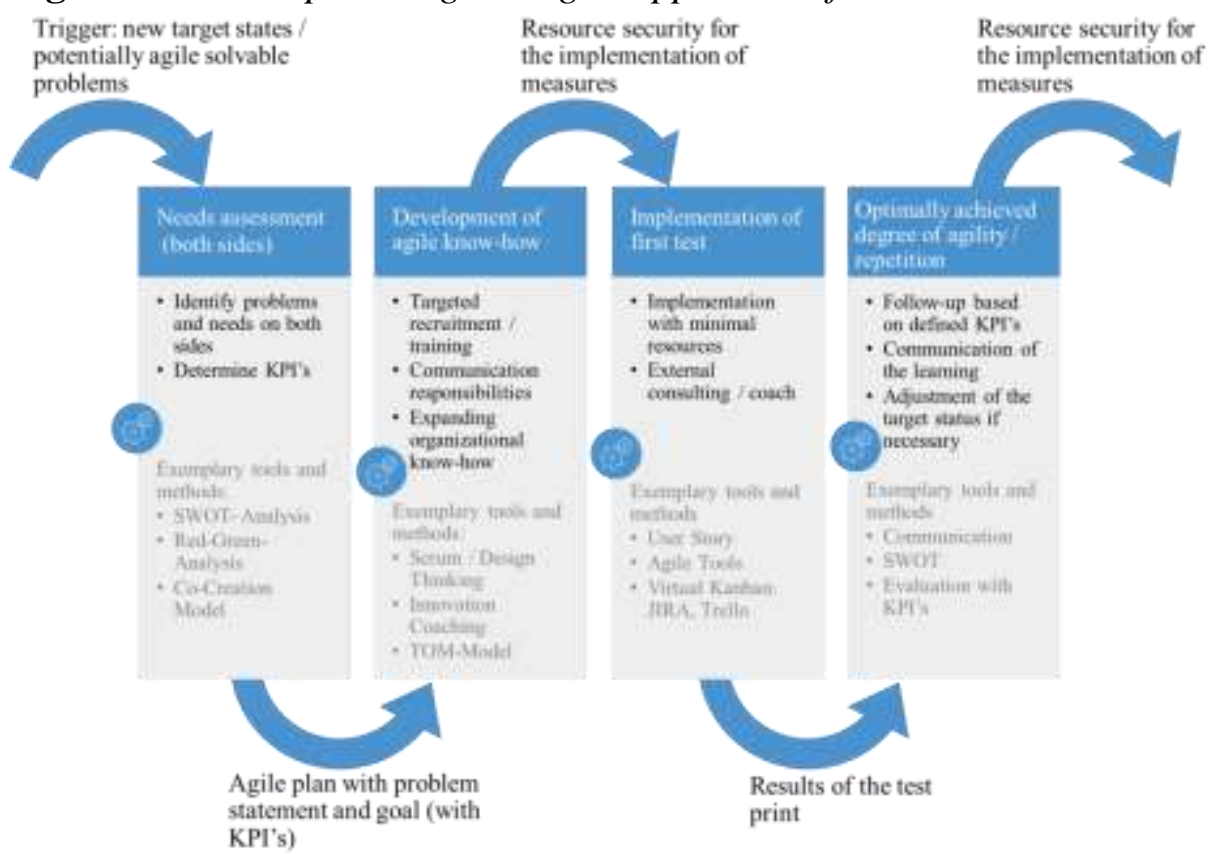


Figure 6 illustrates the four steps of the concept with its in- and output for integrating agile approaches into the product development by the example of the first cluster, companies with no or few agile experience. Exemplary tools and methods which are suitable in these steps are represented by the gears below the steps.

The first step consists of a two-way need analysis in which both, management and product development, analyze what their needs are in the actual situation and whether agile approaches are the right solution. If agile approaches have been chosen with the help of a suitable method, the second step is to build up the knowhow of agile approaches and appropriate methods and tools to create the resources for their application. The third step is a first test sprint of the chosen agile approach (due to the lack of experience of the cluster) with recommended methodological support. In the last step the test sprint is post-processed and the new status quo is validated. The involvement of the management is recommended for a comprehensive understanding of all stakeholders and for a possible decisionmaking in the area of budget or personnel. After the evaluation of the last step, the optimal degree of agility should be reached or the process starts all over again with the determined changes.

\section{$3^{\text {rd }}$ Part of the Concept: Tool and Methods for Integrating Agile Approaches}

As assistance, a collection of tools and methods for implementing the four roadmap steps in the concept is also added as a third part of the concept. Exemplary methods and analysis tools are the SWOT-Method or the Co-Creation model for the need assessment in the first step of the roadmap which are represented in Figure 6 (Anthony et al. 2019, Bormann et al. 2019, p. 136). These tools and methods are only a few of many methods which can be applied for a structured support of implementing the roadmap and thus can be extended as desired.

\section{Discussion and Limitations}

Through the empirical study a research progress was achieved with regard to the current challenges of companies in the integration of agile approaches. Clusterspecific focal points of these challenges were identified. Different problem areas in agile product development were derived which need to be tackled in order to enhance the effective integration of agile approaches. Resulting from the descriptive study, actual challenges of the companies are a lack of knowledge about agile approaches and the application of the corresponding methods. Additionally, the given lack of understanding the purpose and added value of agile approaches prevents a successful implementation. Thus there is a need for support within the management as well as the development team in order to enable a situation- and demand-based application of methods.

Especially within SME's the leadership competence seems to be important. As teams are smaller and communication channels faster the misleading image 
could appear that agile approaches are not necessary. Hence management skills are mandatory in order to integrate a need-driven agile approach. Particularly transparency and open communication within agile development teams must be actively promoted by the management as well as by each team member. This result is comparable with the study results from the state of research which analyzed companies' product development in general.

One of the major advantages of this research is the integration of a needdriven approach. As stated above, SME are not miniature versions of corporates and therefore have different needs when it comes to agile approaches. The knowledge obtained from the expert interviews as well as the validation results within a workshop, indicate the demand of integrating a situation and need specific level of agility into the product development projects. To identify the needs as well as the opportunities by using the presented concept there is a high demand for a process-oriented support of the people working in the early phase of product development projects. This could be ensured by the agglomerative hierarchical clustering (the first part of the concept) and the derived problem-oriented roadmap and tools in our proposed concept.

A potential drawback of this study may be the number of samples. However, here we focus on qualitative expert interviews to ensure highly qualitative data source with high explanatory factor. We do recommend an additional crowdsourced, quantitative interview study as we expect a large differentiation in the (partly unidentified) answers of the actual problem settings. Additional, the information about organizational structures and the type of organizational integration are highly company-specific and sensitive as well, thus they are often not readily revealed.

Due to the main focus of the paper on product development in mechanical engineering, other interesting areas and industries are mostly left out. In the longterm we recommend to transfer the concept to product developments in larger companies or SME's in different industries as they might have similar needs and attributes in their integration of agile approaches. Further research should investigate the use of process oriented support of development teams and help them integrate agile approaches according to the developed roadmap. Coaching approaches that take into account the needs of each team depending on the situation are promising with regard to the goal of introducing an appropriate level of agility.

\section{Conclusion and Outlook}

In this paper we tackled the question of how a concept for integrating agile approaches in product development for different SME requirements needs to be designed. This research gap was narrowed by identifying the actual problems and needs of the SME's. Upon these conclusions a generic and problem-oriented integration concept was developed to consider the different needs of SME's in the context of agile product development. 
In order to increase its validity, the concept was applied and optimized in a workshop with four experts from practice. As a result, the concept including its structure and individual parts was rated "very good" or "good" in regards of its added value, showing the sense of the concept. We further validated, that the methodological support through an internal coach leads to a higher contribution of the current implementation of agile approaches, according to the statements within the workshop discussions. In summary, all research questions within the scope of the paper are answered and the goal of developing a concept with a high generalisation character, which contains need-specific measures and methods for its cluster-specific problems, is achieved.

Concluding, the developed cluster-specific concept represents an initial practical integration and application model of agile approaches for different product developments. Due to the three defined clusters, which are based on the experiences and current expert knowledge of different companies, our proposed concept illustrates a problem-oriented concept with transferability. Thus, the concept defines a basis with high potential to facilitate and optimize the integration and application of agile approaches in product development for every company in the future.

\section{References}

Albers A, Heimicke J, Mueller J, Spadinger M (2019a) Agility and its features in mechatronic system development: a systematic literature review. In Proceedings of the ISPIM Innovation Conference 2019.

Albers A, Heimicke J, Spadinger M, Reiss N, Breitschuh J, Richter T, et al. (2019b) A systematic approach to situation-adequate mechatronic system development by ASD - Agile Systems Design. Procedia CIRP 84(Sep): 1015-1022.

Anthony SD, Cobban P, Nair R, Painchaud N (2019) Breaking down the barriers to innovation. Retrieved from: https://hbr.org/2019/11/breaking-down-the-barriers-to-in novation. [Accessed 21 February 2020.]

Atzberger A, Nicklas SJ, Schrof J, Weiss S, Paetzold K (2020) Agile Entwicklung physischer Produkte. (Agile development of physical products). Technical Report. Neubiberg: Universität der Bundeswehr München

Barafort B, O'Connor Rv, Poth A (Eds.) (2014) Communications in computer and information science. In Systems, Software and Services Process Improvement: $21^{\text {st }}$ European Conference, EuroSPI 2014, Luxembourg, June 25-27, 2014. Proceedings. Berlin/Heidelberg: Springer Berlin Heidelberg.

Berends H, Jelinek M, Reymen I, Stultiëns R (2014) Product innovation processes in small firms: combining entrepreneurial effectuation and managerial causation. Journal of Product Innovation Management 31(3): 616-635.

Bicen P, Johnson WHA (2015) Radical innovation with limited resources in highturbulent markets: the role of lean innovation capability. Creativity and Innovation Management 24(2): 278-299.

Blessing LTM, Chakrabarti A (2009) DRM, a design research methodology. London: Springer London.

Bormann H-W, Benfer M, Bormann G (2019) Change durch Co-Creation: So verdoppeln Sie den Erfolg Ihrer Transformationsprojekte. (Change through co-creation: how to double the success of your transformation projects). $1^{\text {st }}$ Edition. Frankfurt: Campus. 
Cleff T (2019) Applied statistics and multivariate data analysis for business and economics. Springer International Publishing.

Dose N, Drexler A (Eds.) (1988) Technologieparks. (Technology Parks). Wiesbaden: VS Verlag für Sozialwissenschaften.

Fritsch A, Juschkat K (2019) Warum der Maschinenbau agil werden muss. (Why mechanical engineering must become agile). Retrieved from: https://www.Kons truktionspraxis.vogel.de/warum-der-maschinenbau-agil-werden-muss-a-880738/.

[Accessed 29 June 2020.]

Fuchs C, Barthel P, Winter K, Hess T (2019) Agile Methoden in der digitalen Transformation - mehr als ein Konzept für die Softwareentwicklung. (Agile methods in digital transformation - more than a concept for software development). Wirtschaftsinformatik \& Management 11(4): 196-207.

Giom.blog (2019) 3 reasons why agile transformation are too complex for a big plan approach. Retrieved from: https://giom.blog/2019/04/13/transformation-too-comple x-for-big-plan/. [Accessed 23 June 2020.]

Gloger B, Margetich J (2014) Das Scrum-Prinzip: Agile Organisationen aufbauen und gestalten. (The Scrum principle: build and design agile organizations). Stuttgart: Schäffer-Poeschel.

Heimicke J, Niever M, Zimmermann V, Klippert M, Marthaler F, Albers A (2019) Comparison of existing agile approaches in the context of mechatronic system development: potentials and limits in implementation. Proceedings of the Design Society: International Conference on Engineering Design 1(1): 2199-2208.

Kammerlander N, Ganter M (2015) An attention-based view of family firm adaptation to discontinuous technological change: exploring the role of family ceos' noneconomic goals. Journal of Product Innovation Management 32(3): 361-383.

Kammerlander N, Prügl R (2016) Innovation in Familienunternehmen. (Innovation in family businesses). Wiesbaden: Springer Fachmedien Wiesbaden.

Kassambara A (2017) Practical guide to cluster analysis in R: unsupervised machine learning. Volume 1 . Sthda.

Kastelle T (2013) Hierarchy is overrated. Retrieved from: https://store.hbr.org/product/ hierarchy-is-overrated/H00J14. [Accessed 21 February 2020.]

Kotter JP, Cohen DS (2012) The heart of change: real-life stories of how people change their organizations. Boston: Harvard Business Review Press.

Leffingwell D (2020) Scaled agile. The provider of SAFe. Retrieved from: https://www. scaledagile.com/. [Accessed 23 June 2020.]

Lind C (2017) Assessment and design of industrial manual handling to reduce physical ergonomics hazards - Use and development of assessment tools. KTH Royal Institute of Technology.

Massis A de, Audretsch D, Uhlaner L, Kammerlander N (2018) Innovation with limited resources: management lessons from the German Mittelstand. Journal of Product Innovation Management 35(1): 125-146.

Mathis C, Leffingwell D (2018) SAFe - Das Scaled Agile Framework: Lean und Agile in großen Unternehmen skalieren. (SAFe - The scaled agile framework: scaling lean and agile in large enterprises). Heidelberg: dpunkt.

Maximini D (2018) The Scrum culture. Cham: Springer International Publishing.

Nandram SS, Bindlish PK (2017) Managing VUCA through integrative self-management. Berlin: Springer.

Narang T (2017) Finding Clusters of Data: Cluster Analysis in R. In Proceedings of the 5th International Conference on Frontiers in Intelligent Computing: Theory and Applications, 635-640. Singapore: Springer. 
Niever M, Marthaler F, Kosejian M, Hahn C, Albers A (2019). The Future of Innovation coaching in product engineering: a systematic approach to deriving the future competence profile and its development through strategic potential identification. In Proceedings of Collaborative European Research Conference, 299-310.

O'Connor RV, Duchonova N (2014) Assessing the value of an agile coach in agile method adoption. In B Barafort, Rv O'Connor, A Poth (eds.), Communications in Computer and Information Science. Systems, Software and Services Process Improvement. $21^{\text {st }}$ European Conference, EuroSPI 2014, Luxembourg, June 25-27, 2014. Proceedings, 135-146). Berlin/Heidelberg: Springer Berlin Heidelberg.

Plattner H, Meinel C, Leifer L (2011) Design thinking: understand - improve - apply. Understanding innovation. Berlin, Heidelberg: Springer-Verlag Berlin Heidelberg.

Schoeneberg K-P (2014) Komplexitätsmanagement in Unternehmen: Herausforderungen im Umgang mit Dynamik, Unsicherheit und Komplexität meistern. (Complexity management in companies: Mastering challenges in dealing with dynamics, uncertainty and complexity). Wiesbaden: Springer Gabler.

Schwaber K (2017) The Scrum guide. Retrieved from: from https://www.scrumguides.org/ docs/scrumguide/v2017/2017-Scrum-Guide-US.pdf.

Siedl W (2018) SAFe®: Reiseführer zum lean-agilen Unternehmen - Wie Sie mit SAFe® und dem Enterprise Transformation Cycle lean-agile Methoden und Tools in Ihrem Unternehmen einführen. ( $\mathrm{SAFe}{ }^{\circledR}$ : Guide to the lean-agile company - How to introduce lean-agile methods and tools in your company with SAFe ${ }^{\circledR}$ and the Enterprise Transformation Cycle). In MA Pfannstiel, PF-J Steinhoff (eds.), Der Enterprise Transformation Cycle, 73-94). Wiesbaden: Springer Fachmedien Wiesbaden.

Snowden D, Boone M (2007) A leaders framework for decision making. Harvard Business Review (85.11).

VersionOne Inc. (2019) $13^{\text {th }}$ annual state of agile report: a look into the global state of enterprise agile in 2019 (annual state of agile report). Retrieved from: https:// www.stateofagile.com/\#ufh-i-521251909-13th-annual-state-of-agile-report/473508. [Accessed 7 June 2019.]

VersionOne Inc. (2020) 14 th annual state of agile report: a look into the global state of enterprise agile in 2020 (annual state of agile report). Retrieved from: https://stateof agile.com/\#ufh-i-615706098-14th-annual-state-of-agile-report/7027494. [Accessed 29 June 2019.]

Vodde B, Larman C (2005) Overview - Large scale Scrum (LeSS). Retrieved from: https:// less.works/. [Accessed 22 February 2019.]

we.Connect (2018) Perspectives of agile product development processes in the automotive ecosystem - Survey report. we.Connect.

Welsh JA, White JF, Dowell P (1982) A small business is not a little big business. Harvard Business Review 59(4). 